\title{
Correction to: Japanese insurers' attitudes toward adverse selection and genetic discrimination: a questionnaire survey and interviews with employees about using genetic test results
}

Hiroshi lida $\cdot$ Kaori Muto

Published online: 18 December 2020

(c) The Author(s), under exclusive licence to The Japan Society of Human Genetics 2020

Correction to: Journal of Human Genetics

https://doi.org/10.1038/s10038-020-00873-y
In the original publication of the article, the second author's name was incorrect. The correct name is Kaori Muto, not Kori Muto. 